\title{
UTILIZAÇÃO DE LIVES COMO FERRAMENTA DE EDUCAÇÃO EM SAÚDE DURANTE A PANDEMIA PELA COVID-19
}

\author{
Vanusa Nascimento Sabino Neves ${ }^{1}$ \\ Charliton José dos Santos Machado ${ }^{2}$ \\ Lia Machado Fiuza Fialho ${ }^{3}$ \\ RAQUEl do NASCIMENTO SABINO ${ }^{4}$
}

\begin{abstract}
RESUMO: Objetivou-se compreender a experiência formativa realizada por meio de lives, com a temática "educação em saúde", durante o confinamento social imposto pela Covid-19. Desenvolveu-se uma pesquisa de abordagem qualitativa, do tipo pesquisa-ação, que utilizou lives como veículo para a ação formativa. Realizaram-se nove lives: a maioria dos conteúdos educativos veiculados partiu da demanda do hospital e versava sobre o enfrentamento da Covid-19. Concluiu-se que as lives se apresentam como ferramentas importantes para operacionalizar a educação permanente em saúde, especialmente em contexto de pandemia, no entanto, elas excluem usuários do sistema público de saúde de maior vulnerabilidade social, que não possuem acesso à tecnologia móvel conectada à Internet.
\end{abstract}

Palavras-chave: Educação em saúde. Lives. Covid-19. Pandemia. Pesquisa-ação.

\section{USE OF LIVES AS A HEALTH EDUCATION TOOL DURING THE COVID-19 PANDEMIC}

\begin{abstract}
The objective was to understand the training experience carried out through online live videos called lives with the theme "health education", during the social confinement imposed by COVID-19. A qualitative research-action was developed, which used lives as a vehicle for formative action. Nine lives were held: most of the educational content conveyed came from the demand of the hospital and dealt with coping with COVID-19. It is concluded that lives are presented as important tools to operationalize permanent health education, especially in the context of a pandemic. However, they excluded users of the public health system of greatest social vulnerability, who do not have access to mobile technology connected to the Internet.
\end{abstract}

Keywords: Health education. Lives. COVID-19. Pandemic. Action research.

1.Hospital da Polícia Militar General Edson Ramalho - João Pessoa (PB), Brasil. E-mail: pbvanusa@gmail.com

2.Universidade Federal da Paraíba - Centro de Educação - Departamento de Metodologia da Educação - João Pessoa (PB), Brasil. E-mail: charlitonlara@yahoo.com.br

3.Universidade Estadual do Ceará - Centro de Educação/Programa de Pós-Graduação em Educação - Fortaleza (CE), Brasil. E-mail: lia_fialho@yahoo.com.br

4.Secretaria Municipal de Educação - João Pessoa (PB), Brasil. E-mail: raquelsabino26@gmail.com

Editor de Seção: Antônio Álvaro Soares Zuin 


\title{
USO DE LIVES COMO HERRAMIENTA DE EDUCACIÓN PARA LA SALUD DURANTE LA PANDEMIA COVID-19
}

\begin{abstract}
RESUMEN: Se objetivó comprender la experiencia de capacitación realizada mediante lives con el tema "educación para la salud" durante el encierro social impuesto por el COVID-19. Se desarrolló una investigación cualitativa de investigación-acción, que utilizaba lives como vehículo para la acción formativa. Se realizaron nueve lives: la mayor parte del contenido educativo transmitido provino de la demanda del hospital y se ocupó de hacer frente al COVID-19. Se concluyó que las lives se presentan como herramientas importantes para poner en práctica la educación permanente en salud, especialmente en el contexto de una pandemia; sin embargo, excluyen a los usuarios del sistema de salud pública de mayor vulnerabilidad social, que no tienen acceso a la tecnología móvil conectada a Internet.
\end{abstract}

Palabras-clave: Educación para la salud. Lives. COVID-19. Pandemia. Investigación-acción.

\section{Introdução}

$\mathrm{E}$

m 30 de janeiro de 2020, a Organização Mundial de Saúde (OMS) emitiu para o mundo seu mais alto nível de alerta, por meio de declaração inferindo que o surto pela Covid-19, doença provocada pelo coronavírus da Síndrome Respiratória Aguda Grave 2 (SARS-CoV-2), é uma emergência de saúde pública de importância internacional (PAHO, 2020). No entanto, desde dezembro de 2019, o mundo já acompanhava a divulgação dos casos de Covid-19 a partir do epicentro mundial, em Wuhan, na China (GUY et al., 2020).

Uma avalanche contínua de informações preocupantes passou a fazer parte do cotidiano das pessoas, entre as quais o fato de que a doença ainda não é bem compreendida pela comunidade médica e científica. Sabe-se, todavia, que é contagiosa e sem tratamento preventivo e curativo específicos; em algumas pessoas mais vulneráveis, provoca uma grave pneumonia aguda, podendo levar à fatalidade (BAI et al., 2020).

Ante esse cenário desafiador, o Brasil, por intermédio da Lei n. 13.979, de 6 de fevereiro de 2020, lançou diversas medidas para o enfrentamento dessa emergência. Entre tantas outras, foram recomendadas as estratégias do isolamento social e da quarentena, a fim de proteger a coletividade e reduzir a velocidade de contágio. Todavia, a despeito da atenção de diversas autoridades administrativas e de saúde, a doença continuou a avançar com velocidade inimaginável por todos os continentes. Assim, a OMS, em 11 de março de 2020, caracterizou a Covid-19 como uma pandemia. Conforme dados que estão em constante atualização, em 12 de fevereiro de 2021, a OMS confirmou, no mundo, 107.423.526 pessoas infectadas pelo SARS-CoV-2 e 2.360.280 mortes em decorrência de complicações pela Covid-19 (PAHO, 2021). No Brasil, nessa mesma data, foram confirmados 10.195 .160 casos e 247.143 óbitos, cumulativamente (BRASIL, 2021).

De acordo com Estelles e Fischman (2020), a pandemia tem imposto aos diversos setores da sociedade desafios em escala cada vez maior, não apenas para os que atuam na seara hospitalar, ainda que esses sejam os mais desafiados, mas também para os educadores, já que:

[...] en este sentido, una mirada sociocultural y crítica del campo pedagógico nos interpela a repensar no solo el espacio limitado de las aulas y las escuelas, sino a reconfigurar un territorio 
en el que el mundo opera como pedagogía, salir de opciones metodológicas homogeneizantes $y$ miradas restringidas sobre los procesos de enseñar y aprender (DI FRANCO et al., 2020, p. 13). ${ }^{1}$

Di Franco et al. (2020) explicam que a pandemia causada pela Covid-19 torna factível pensar criticamente o campo pedagógico, pois a educação transcende os espaços físicos da escola e começa, mais fortemente, a operar mediante outras opções metodológicas. No caso específico do Brasil, em sendo um território com dimensões continentais, de elevada variabilidade e vulnerabilidade social e de cultura bastante heterogênea, essa situação tem complexidade muito maior (SANTOS, 2020).

Além das dificuldades projetadas sobre a seara da saúde, o campo educacional também sente os impactos da pandemia: aulas presenciais foram suspensas; professores, pais e alunos tiveram que, repentinamente, adotar as estratégias de ensino por intermédio das Tecnologias da Comunicação e Informação (TCI); e docentes se viram obrigados a trabalhar de maneira mais enfática a educação em saúde para colaborar com a prevenção da Covid-19. Não se ignora, todavia, como lembram Bittencourt, Fialho e Ponce (2020), que se faz necessário, para a utilização das TCI no campo educacional, que alunos e professores disponham de equipamentos digitais com acesso à Internet, para além da habilidade de operacionalizar tais ferramentas. Essa situação se agrava para boa parte das famílias com baixo poder aquisitivo, em especial residentes de zonas rurais, ribeirinhos e demais populações mais afastadas dos centros urbanos, para quem a práxis educacional possui outras singularidades (GONÇALVES; NOGUEIRA, 2017; FONSECA; BIERHALZ, 2018; ZUIN; DIAS, 2017).

A pandemia da Covid-19 tem mudado diversos padrões da sociedade, entre os quais o modo de comunicação das pessoas, a exemplo do aumento das transmissões em tempo real por meio de redes sociais, transmissões essas impulsionadas pela campanha "Fique em Casa". Essa maneira de se relacionar, mediante o distanciamento social, passou a ser utilizada em grande escala, inclusive por autoridades, artistas, professores e diversos outros profissionais (DI FRANCO et al., 2020). Entre as ferramentas disponibilizadas nas redes sociais, uma especialmente chama a atenção para o desenvolvimento desta pesquisa: o uso das lives.

Questionou-se se a live poderia se efetivar como uma ferramenta apropriada para fomentar a educação em saúde durante o confinamento social. Ao refletir sobre possíveis potencialidades e desafios que as transmissões ao vivo podem apresentar, elaborou-se uma pesquisa científica com o objetivo de compreender a experiência formativa realizada por meio de lives com a temática "educação em saúde" durante o confinamento social imposto pela Covid-19, mediante parceria constituída entre profissionais de um hospital público estadual de médio porte da cidade de João Pessoa, Paraíba (PB), e professores da Universidade Federal da Paraíba (UFPB) e da Universidade Estadual do Ceará (UECE). O público-alvo constituiu-se de profissionais de educação e saúde, bem como de pessoas da comunidade interessadas em participar das lives no período de $1^{\text {o }} 31$ de maio de 2020. Partiu-se do pressuposto de que ações educativas sobre prevenção, diagnóstico e cuidado com a Covid-19 poderiam colaborar para a disseminação de informações confiáveis, bem como para a formação de profissionais para a propagação da educação em saúde.

A relevância da pesquisa centra-se no combate aos reflexos deletérios da pandemia, que se contrapõem aos dezessete Objetivos de Desenvolvimento Sustentável (ODS) globais e suas 169 metas propostas para serem alcançadas até 2030. De acordo com a Organização das Nações Unidas Brasil (ONUBR, 2015), as metas dos ODS são integradas e indivisíveis e, especialmente no tocante à educação em saúde, cumpre enfatizar os ODS de número 3 e 4, que se referem, respectivamente, a saúde e bem-estar e à educação de qualidade. O primeiro, mediante treze metas, convoca a todos para empreender esforços colaborativos com a finalidade de assegurar uma vida saudável e promover o bem-estar para todas as pessoas em todas as idades. O segundo, por meio de dez metas, pretende assegurar educação inclusiva, equitativa e de qualidade e promover oportunidades de aprendizagem ao longo da vida para todos. Nessa direção, a pesquisa-ação 
em relato torna factível colaborar com a educação em saúde com vistas a promover espaços educativos para ampliar os conhecimentos de profissionais de saúde, professores e demais interessados em melhor compreender como lidar com a Covid-19, subsidiando uma práxis educativa mais fundamentada.

Importa destacar que, de acordo com a Organização das Nações Unidas para a Educação, a Ciência e a Cultura (UNESCO, 2020b), no painel de monitoramento mundial do fechamento das escolas em virtude da Covid-19, em consulta realizada em 23 de junho de 2020, o impacto na educação brasileira afetou 52.898.349 estudantes da educação básica ao nível superior. A suspensão das aulas é particularmente grave para os estudantes vulneráveis e marginalizados, porque há despreparo para a Educação a Distância $(\mathrm{EaD})$ e, em casa, professores, pais e alunos convivem com confusão de papéis, entre tantos outros problemas decorrentes do acesso às tecnologias móveis, à Internet de qualidade etc. (UNESCO, 2020a). O Brasil, além do comprometimento com o alcance dos dezessete objetivos da Agenda 2030, preconizados nos ODS, precisa atender às políticas públicas relacionadas à educação em saúde, por exemplo, a Política Nacional de Educação Permanente em Saúde (PNEPS) e a Política Nacional de Educação Popular em Saúde (PNEPS-SUS).

Salienta-se que a PNEPS foi instituída pelo Ministério da Saúde mediante a Portaria n, 198, do Gabinete do Ministro do Ministério da Saúde (GM/MS), de 13 de fevereiro de 2004, com o propósito de ser a estratégia do Sistema Único de Saúde (SUS) para a continuidade da formação de seus trabalhadores. Entre várias diretrizes, a PNEPS estabelece que a condução do processo educacional para os profissionais, diferentemente das práticas educacionais tradicionais caracterizadas pela transmissão passiva de saberes pré-elaborados, deverá ser conduzida de forma problematizadora, descentralizada, transversal e interdisciplinar (BRASIL, 2004).

Por seu turno, a PNEPS-SUS foi instituída pela Portaria n. 2.761, de 19 de novembro de 2013, para afirmar o comprometimento com a universalidade, a integralidade, a equidade e a efetiva participação popular no SUS. Nesse propósito, preconiza-se uma prática político-pedagógica fundamentada no diálogo entre a multiplicidade de saberes populares ancestrais, incentivando a produção compartilhada de conhecimentos e a inserção desses no SUS (BRASIL, 2013).

Na perspectiva dos ODS, da PNEPS e da PNEPS-SUS, o processo de trabalho em educação em saúde, a partir da identificação das necessidades práticas e teóricas, deve ser conduzido de maneira coletiva e compartilhada, envolvendo profissionais de diversas áreas de forma interdisciplinar. Refletir sobre a educação em saúde e formular estratégias que produzam ações educativas resolutivas das demandas e lacunas existentes no ambiente social e de trabalho devem ser compromissos de todos. Além disso, como o conceito de educação permanente em saúde conecta trabalho e educação, torna-se essencial a indissociabilidade entre as áreas de Saúde e Educação como princípio estratégico para a consolidação do SUS e o enfrentamento da pandemia (BRASIL, 2018).

$\mathrm{Na}$ encruzilhada entre a contraindicação de encontros educativos presenciais (graças ao risco de disseminação do vírus) e a necessidade premente de maior qualificação profissional para bem atuar diante das novas evidências científicas (que são adicionadas continuadamente, ditando a reformulação da prática científica assistencial especifica à Covid-19), as lives, além de contribuir para o processo formativo dos profissionais da saúde, em termos dos padrões éticos e sanitários, pode também capacitar os integrantes da comunidade para a autonomia do cuidado, da prevenção e da promoção da saúde, desde que possibilitem a atitude crítica e reflexiva, pela interface com a educação em saúde. Desse modo, as lives ganham sentido formativo de importância no contexto atual, na medida em que se transformam em momentos propícios para a reflexão e a discussão de conhecimentos e práticas que fortaleçam uma práxis mais crítica e consciente, pois permitem compreender melhor não apenas o estado pandêmico e os cuidados requeridos para combater a propagação do vírus, mas também a indissociabilidade desse contexto com a educação, reinventando modelos formativos e incorporando novos processos educacionais viáveis e pertinentes. 


\section{Metodologia}

A pesquisa realizada utilizou a abordagem qualitativa (MINAYO, 2007), descritiva (GIL, 2017), do tipo pesquisa-ação (TRIPP, 2005), e utilizou como técnica de coleta de dados a observação participante (SOMEKH; JONES, 2015) para a análise da ação-formação. O cuidado com a descrição meticulosa tanto da ação interventiva como da observação participante foi adotado por ser fundamental em pesquisas que partem de um problema real previamente identificado para desenvolver uma ação planejada com o objetivo definido, posto que analisa os resultados encontrados considerando as especificidades de um contexto específico.

A pesquisa acerca da utilização de transmissões em tempo real, lives, como instrumento de educação permitiu não apenas o relato da experiência formativa de maneira qualitativa e descritiva, mas a constituição compartilhada do conhecimento entre educadores e profissionais da saúde em análises interdisciplinares sobre um problema que abrange a sociedade como um todo, em suas múltiplas dimensões: a pandemia causada pela Covid-19. Sobre a constituição compartilhada do conhecimento, esse conceito emerge da PNEPS-SUS, ao inferir que ele "[...] consiste em processos comunicacionais e pedagógicos entre pessoas e grupos de saberes, culturas e inserções sociais diferentes, na perspectiva de compreender e transformar de modo coletivo as ações de saúde desde suas dimensões teóricas, políticas e práticas” (BRASIL, 2013, art. 4º).

Para Minayo (2007), a tipologia qualitativa propicia a compreensão mais detalhada de uma realidade, pois, ao reduzir a lente de análise, torna-se factível refletir significados e nuances de contextos específicos não captados em pesquisas quantitativas. Ao adotar a pesquisa-ação nesta abordagem, consoante Tripp (2005), permite-se que o processo de pesquisa possa inter-relacionar o agir no campo da prática e a investigação a respeito dela, tornando factível a alteração da realidade que está sendo pesquisada, uma vez que o conhecimento obtido na ação-formação serve a todos os envolvidos - pesquisadores e participantes. Desse modo, a pesquisa-ação gera conhecimento teórico e subsidia a transformação prática; ou seja, efetiva a "pesquisa-como-ação" (COOKE, 1945), que visa corroborar a instrumentalização social crítica, contornando limitações e desigualdades quando associada às tecnologias digitais (FANTIN, 2017). Késia et al. (2019) acrescentam que a pesquisa-ação emancipatória, aquela desenvolvida na perspectiva crítica, também constitui ato político, visto que possibilita mudar o status do conhecimento de um grupo social.

De acordo com Gil (2017), as pesquisas descritivas são relevantes porque caracterizam detalhadamente um fenômeno e estabelecem as relações entre as suas variáveis, considerando o contexto específico em que se inserem; logo, não são apenas viáveis, mas comumente utilizadas por pesquisadores sociais interessados na atuação prática. O processo descritivo dos dados produzidos foi efetivado com o auxílio da observação participante, técnica de obtenção de dados por meio dos sentidos (MARCONI; LAKATOS, 2011). Somekh e Jones asseveram a relevância dessa técnica quando defendem que ela é:

[...] um dos métodos mais importantes de coleta de dados. Ela implica estar presente em uma situação e registrar as impressões causadas pelo que acontece. O principal instrumento de pesquisa é o eu, que colhe conscientemente dados mediante a visão, o ouvido, o gosto, $o$ cheiro e o toque.

Quanto à observação na modalidade participante, o investigador e os colaboradores estão no mesmo cenário, e os dados são obtidos diretamente do contexto ou na situação específica do grupo, nesse caso, durante a realização das lives, que, inclusive, foram gravadas para possibilitar refinar as observações e análises a posteriori (2015, p. 183). 
Ainda que as lives sejam projetadas on-line, o principal local do estudo foi um hospital estadual de médio porte localizado em João Pessoa, na Paraíba. O estudo obteve anuência formal da diretoria do hospital para relatar a experiência investigativa e contou com a colaboração de profissionais da área da educação de duas instituições de Ensino Superior - UFPB e UECE -, as quais se articulavam por meio de grupos de pesquisa que estudam práticas educativas, leituras e representações de educadores tecidas no Nordeste brasileiro. Juntos, profissionais da saúde e da educação, por meio de articulação virtual, planejaram, desenvolveram e analisaram a realização de lives para a educação em saúde em torno da temática Covid19. Ressalte-se que foram respeitados os critérios éticos de pesquisa; logo, a identidade dos participantes foi preservada, assegurando o anonimato. Além disso, toda a definição dos objetivos, a coleta e a análise dos dados se deram com o consentimento e o acompanhamento da gestão institucional (CRESWELL, 2007).

\section{Resultados: A Descrição da Ação}

A pesquisa-ação foi concretizada neste estudo mediante cinco fases: 1) da articulação; 2) do planejamento; 3) da divulgação; 4) da operacionalização; e 5) da avaliação. Todas essas fases são descritas a seguir.

\section{Fase da Articulação}

Com o avanço da pandemia pelo novo coronavírus, foi necessário reformular a maneira de fazer educação permanente em saúde no hospital lócus deste estudo, já que havia um impasse: de um lado, a urgência necessária ao plano de contingência institucional para o enfrentamento da Covid-19, especialmente no atendimento aos infectados; do outro, a necessidade da manutenção das atividades educativas peculiares à educação permanente em saúde, ainda mais urgentes em tempos de uma doença desconhecida que assusta a população.

A partir de diálogo com o diretor executivo e com a assessoria de comunicação e marketing do hospital em busca de estratégias para a continuidade das ações educativas pelo Núcleo de Educação Permanente em Saúde (NEPS), efetivou-se a proposta das transmissões ao vivo como ferramenta para a continuidade das atividades educativas presenciais, que haviam sido suspensas por causa da pandemia, dessa vez, com foco na Covid-19.

Com o mote de reunir parceiros e consolidar uma educação em saúde interdisciplinar, convidaram-se docentes universitários com expertise em pesquisa científica e formação de professores para somar esforços na promoção da educação em saúde, numa oportunidade de associar conhecimentos didáticos e educacionais com conhecimentos em saúde para fornecer a outros profissionais e à comunidade local educação em saúde de maneira on-line.

\section{Fase do Planejamento}

Preliminarmente, revisitou-se o conteúdo programático existente no plano de educação permanente do hospital elaborado pelo NEPS para o exercício 2020/2021, cotejado com as novas demandas educacionais informadas pelos diretores, pelos gerentes e pelos próprios profissionais em abril de 2020. Havendo a constatação de que a maioria delas estava relacionada à Covid-19, tomou-se a decisão de atender à urgência dessa temática com a realização de lives com caráter educativo, pois a formação presencial já não era mais segura e o agravamento da Covid-19 e do isolamento social exigia ações urgentes. 
Partiu-se em busca de profissionais para realizar as atividades educativas on-line, moderadores e debatedores. Formularam-se convites aos gerentes do próprio hospital, tendo alguns aceitado e outros se declarado inexperientes para usar as TCI, em particular, com transmissões em tempo real. Entretanto, que profissional técnico assistencial do hospital dispunha de experiência com lives? Cabe pontuar o fato de que foram formados para ser profissionais da saúde, técnicos multiprofissionais assistenciais, em trabalho presencial, o que tornava as competências com as ferramentas digitais ainda restritas para muitos.

Os convites foram estendidos a professores da UFPB que voluntariamente se puseram disponíveis paracolaborarcompesquisascomatemáticaCovid-19.A partirdessecontato, sugeriu-seampliaraarticulaçãopara envolver profissionais da UECE, já que esses profissionais participavam de projetos colaborativos e interinstitucionais, reunindo esforços para a realização de lives educativas o mais qualificadas possível. Dessa forma, a programação mensal foi constituída após reuniões e debates on-line que pensaram duração, horário, metodologia, temática, divulgação, entre outros aspectos de logística.

Quanto ao horário de realização, optou-se pelas 20 horas, a fim de proporcionar o acompanhamento domiciliar on-line das transmissões pelos egressos do expediente de trabalho diurno. Para aqueles impedidos de assistir em tempo real, as transmissões foram gravadas pelo IGTV, um aplicativo de vídeo do Instagram para os sistemas operacionais Android e IOS (iPhone) que possibilita a gravação de vídeos de até 60 minutos de duração e compartilhamento no feed do usuário do Instagram para acesso e visualização posteriores. Em decorrência do tempo permitido para a gravação e da necessidade de objetividade e dinamismo nas transmissões, o tempo para cada live era de no máximo uma hora.

No período de $1^{\circ}$ a 31 de maio de 2020, foram planejadas e realizadas nove lives. A metodologia adotada foi subdividir cada live de 60 minutos em quatro momentos: a) 5 minutos iniciais para cumprimentos, boas-vindas e apresentação do debatedor; b) 40 minutos para o desenvolvimento do tema principal; c) 10 minutos para respostas às perguntas ou leituras das considerações encaminhadas pelo link do story ou durante a exibição da transmissão; e d) 5 minutos para as considerações finais.

O conteúdo abordado foi recomendado conforme as necessidades loco-regionais. Isto é, em conformidade com as carências referidas pelos membros da equipe de saúde, por indicações da diretoria hospitalar e dos gerentes do hospital, sendo os principais temas: qualificação da atenção ao neonato e reflexão sobre as experiências do cuidado humanizado na Unidade de Terapia Intensiva Neonatal (UTIN); "Quando é você quem cuida, quem cuida de você?"; a psicologia na abordagem para os profissionais do enfrentamento à Covid-19; o enfrentamento da Covid-19 pelos profissionais que atuam no serviço de obstetrícia; a atuação da equipe de enfermagem na linha de frente da pandemia; as experiências do posto de coleta de leite humano com enfoque na amamentação e na doação de leite materno durante a vigência da pandemia pelo novo coronavírus; os desafios atuais da assistência de enfermagem nos serviços de urgência e emergência; o impacto da Covid-19 na saúde mental dos profissionais de saúde; e a função do Núcleo Interno de Regulação (NIR).

\section{Fase de Divulgação}

A divulgação se deu mediante o compartilhamento dos banners virtuais pelo aplicativo multiplataforma de mensagens WhatsApp e nas redes sociais virtuais, Instagram e Facebook, do hospital com no mínimo 48 horas de antecedência do evento. Além do mais, no dia de cada transmissão, utilizaram-se stories no Instagram dos profissionais envolvidos e lembretes nos grupos de WhatsApp para incentivar a participação.

Para facultar os debates, nos stories do Instagram do hospital, canal principal de transmissão, foi disponibilizado um link para perguntas prévias, sem excluir a opção de envio de perguntas durante as transmissões on-line por meio de chat. 


\section{Fase de Operacionalização}

$\mathrm{Na}$ operacionalização, moderador e debatedores participaram de suas próprias casas, utilizando seus computadores ou smartphones e a Internet residencial ou do celular. Recomendou-se priorizar Internet de banda larga domiciliar, bem como selecionar ambiente iluminado e silencioso.

Para aqueles ainda carentes de habilidade para com o manuseio das ferramentas digitais, a assessoria de comunicação e marketing do hospital forneceu orientação para acesso a partir de smartphone. Eis o passo a passo formativo:

- Passo 1: realizar acesso ao Instagram institucional e selecionar o ícone de câmera, localizado na extremidade superior esquerda da tela do smartphone;

- Passo 2: quando a tela da câmera abrir, selecionar a opção "ao vivo", na parte inferior da tela do smartphone. Nesse momento, o Instagram informará quantos e quais seguidores estão on-line;

- Passo 3: selecionar a opção “iniciar transmitir ao vivo" pelo botão "iniciar”, localizado na parte inferior da tela. Após esse procedimento, o próprio Instagram automaticamente informará aos seguidores que estiverem on-line que o vídeo ao vivo está sendo iniciado. É uma espécie de convite para os seguidores interessados acessarem a live;

- Passo 4: como, até então, só estará ao vivo o moderador, será necessário introduzir na live o profissional debatedor, o que poderá ser feito de duas maneiras: a) o profissional debatedor, ao acessar a live, solicita participar ao vivo e o moderador autoriza; ou b) o moderador seleciona o ícone com dois rostos, situado na parte inferir da tela do smartphone, e digita o perfil do debatedor. Havendo mais de um debatedor, o moderador finaliza um para introduzir o subsequente, visto que o Instagram possibilita concomitantemente lives de dupla;

- Passo 5: para finalizar a live, seleciona-se o botão encerrar. Nesse instante, surgirá a mensagem "o vídeo foi encerrado" e, com ela, as opções "excluir o vídeo", "baixar o vídeo" ou "compartilhar no IGTV", aplicativo de vídeo previamente instalado no smartphone. A recomendação é compartilhar no IGTV, porque, dessa maneira, o conteúdo será compartilhado no feed do usuário e, assim, permanecerá para acesso futuro pelos seguidores que não tiveram a oportunidade de acompanhar on-line.

Ante a explicação prévia, presencial ou a distância, de acordo com a necessidade dos moderadores e debatedores, o encaminhamento das orientações explicativas supracitadas e a possibilidade de teste fictício de live para treino, a assessoria de comunicação e marketing do hospital possibilitou formação adequada, constatada pela ausência de intercorrências nas nove lives desenvolvidas no mês de maio.

A audiência média sustentada por todo o tempo de transmissão foi de aproximadamente sessenta pessoas. Como o Instagram institucional é de segmento aberto, a audiência foi composta por profissionais da saúde, educadores e demais seguidores, inclusive usuários do serviço e membros da comunidade de maneira geral. Entretanto, até o dia 31 de maio de 2020, os vídeos gravados e disponibilizados no feed do usuário do Instagram institucional alcançaram mais de 8.855 visualizações.

\section{Fase de Avaliação}

A avaliação foi qualitativa e considerou a observação participante, que registrou o interesse demonstrado pelos participantes, a regularidade na participação on-line e a interação social_por meio das 
perguntas depositadas previamente nos stories ou em tempo real no chat. No mais, avaliou-se também, com atenção especial, o número de acessos a posteriori aos vídeos salvos pelo aplicativo IGTV no feed do usuário do Instagram institucional. Isso permitiu refletir sobre o que foi trabalhado na pesquisa-ação, bem como dificuldades e possibilidades na continuidade desses processos formativos, ao considerar as apropriações experienciadas com vistas a ampliar e problematizar outras situações de intervenção, que podem efetivar-se em diversos âmbitos do contexto sócio-histórico - educacional, político, cultural etc.

\section{Discussão}

A realização das nove lives com temas de educação em saúde durante o confinamento social imposto pela pandemia de Covid-19 alcançou on-line cerca de quatrocentos profissionais e usuários dos serviços de saúde em tempo real. Isso porque o público das lives variava bastante, de acordo com a temática. No entanto, importa ressaltar que os vídeos gravados no feed do usuário do Instagram institucional do hospital são acessados diariamente por diversas outras pessoas, gerando milhares de visualizações.

Todo o processo foi desenvolvido pelo método da construção compartilhada de maneira interdisciplinar, envolvendo profissionais da gestão, da comunicação, da educação, da enfermagem, da medicina, da fisioterapia, entre outros. A diretoria do hospital incentivou e participou ativamente de todas as fases das transmissões, ora como moderadora, ora como debatedora. A assessoria de comunicação e marketing do hospital construiu os banners virtuais e contribuiu não apenas com a divulgação, mas com a orientação da parte técnico-operacional. Os gerentes setoriais e profissionais de saúde do hospital participaram como moderadores e debatedores. Professores da UFPB e da UECE, além de participarem do planejamento e da organização do conteúdo do curso, realizaram debates nas lives e acompanharam seu desenvolvimento, sugerindo formas de dinamizar as apresentações e qualificá-las. Mais enfaticamente, esses últimos trabalharam na escrita científica e na divulgação dos resultados da pesquisa-ação.

Emerge da experiência aqui relatada que a pandemia de Covid-19 tem exigido da sociedade em geral, com urgência, a reformulação de modelos adotados em vários segmentos sociais, afinal,

[...] en tiempos de Covid-19, llamamos a reconstituir pedagogías que apuesten por sentidos vitales; afectivas y afectantes, sensibles y atentas al mundo, generadoras de otras posibles narrativas experienciales acerca de esos mundos, como formas de vivir y sentir en tiempos turbulentos, pero también de pensar y experienciar futuros posibles fuera del laberinto (DI FRANCO, et al., 2020, p. 16). ${ }^{2}$

Não obstante a conjuntura desafiadora em razão dos problemas instituídos ou revelados com o avanço da doença, ressalta-se, como mencionado por Neves (2013), que os profissionais da saúde, no dia a dia laboral, ainda convivem com várias fragilidades que o sistema de saúde apresenta. Uma dessas vulnerabilidades é atinente à questão da formação e da aprendizagem profissional qualificadora da assistência à saúde (SOUZA; BRITO, 2013). Sendo assim, as transmissões on-line dos temas educativos se apresentaram com possibilidades promissoras para a continuidade do fluxo de capacitação em saúde, sem perder de vista os pilares estruturantes das políticas públicas vigentes no SUS.

Cumpre esclarecer que, no contexto do SUS, a educação permanente em saúde corresponde a todo o processo de aprendizagem profissional articulado com a realidade vivenciada pelos profissionais no trabalho. Já a educação em saúde se refere à capacitação de qualquer um, profissional ou não, para a adoção de práticas benéficas à saúde individual e coletiva. Ou melhor, como consta no Glossário Temático: Gestão do Trabalho e da Educação na Saúde, 
[...] processo educativo de construção de conhecimentos em saúde que visa à apropriação temática pela população e não à profissionalização ou à carreira na saúde. Conjunto de práticas do setor que contribui para aumentar a autonomia das pessoas no seu cuidado e no debate com os profissionais e os gestores a fim de alcançar uma atenção à saúde de acordo com suas necessidades (BRASIL, 2012, p. 19).

Em primazia aos princípios norteadores do SUS, as demandas de capacitação foram formatadas de acordo com as necessidades identificadas por diretores, gerentes e profissionais. Para Neves (2013), a implementação das ações educativas profissionais, para cumprir os objetivos da PNEPS, deve vincular descentralização, horizontalidade, transdisciplinaridade e incentivo à adoção de técnicas de ensino e aprendizagem problematizadoras.

Freire (2011) ensina que a educação permanente acontece a partir da inclusão do homem e do despertar, em si mesmo, da consciência dessa inclusão; ou seja, o sujeito consciente de si e do mundo é autodirigido a buscar ser mais, a conhecer mais. Como pessoas não são tábuas vazias, todos devem estar articulados e juntos construir o conhecimento considerando o ambiente e suas necessidades. Nesse processo, o papel do educador é orientar o educando para a humanização, no viés da cidadania global, especialmente em tempos em que "[...] a pandemia da Covid-19 criou condições sem precedentes em todas as áreas da vida social” (ESTELLES; FISCHMAN, 2020, p. 1).

As transmissões on-line, disponibilizadas mundialmente via Internet, foram estabelecidas em substituição ao que antes era desenvolvido presencialmente, com contato físico, em ambiente predeterminado, de maneira emergencial, adaptando-se às novas condições de isolamento para minimizar a transmissão e as mortes ocasionadas pela pandemia. Sobre esse dinamismo, Delors (1998) alude que a educação ao longo da vida responde ao desafio imposto pelo mundo em constante transformação, mas não é uma conclusão inovadora; pelo contrário, é uma exigência contínua que hoje, mais do que nunca, adquiriu muito mais razão de ser. Pela aprendizagem profissional, possibilitam-se competências mais amplas, capazes de preparar o adulto para as situações inusitadas do cotidiano laboral, proporcionando e desenvolvendo continuadamente competências e qualificações necessárias às demandas trabalhistas que se apresentam (VERAS; FERREIRA; LOURINHO, 2019).

$\mathrm{Na}$ impossibilidade de se seguir com os encontros educativos presenciais, alternativamente recorreram-se às lives, o que resultou na participação ativa de diretores, gerentes, profissionais da saúde, da comunicação e da educação, bem como de usuários, indicando a descentralização do aprender a aprender e a ensinar. Percebeu-se que foi envolvido um público - de profissionais - que estava ausente nas ações em educação em saúde presenciais, inclusive participando ativamente na produção e na disseminação do conhecimento. Por esse ângulo, Freire explica que "[...] ensinar não é transferir conhecimento, mas criar as possibilidades para a sua própria produção ou a sua construção" (2002, p. 21).

A educação em saúde mediada pela Internet, com utilização de lives, não apenas ampliou e modificou as formas de aprender e ensinar, mas tornou factível a comunicação virtual, propiciando interações no tempo e no espaço com maior liberdade de adaptação aos ritmos diferentes entre quem aprende e quem ensina, ampliando a rede de contato e a interdisciplinaridade mesmo com corpos fisicamente distantes. Por conseguinte, interfaces entre o presencial e o virtual são constituídas, o que permitiu manter os aprendentes juntos e interligados, independentemente da distância física (MORAN, 2013).

Inclusive, a inaptidão inicial para o manejo de ferramentas tecnológicas, demonstrada por alguns profissionais do hospital, foi um desafio superado por todos os que se disponibilizaram a aprender. Afinal, ensinar pressupõe um aprendizado constante. Kenski (2003), nessa direção, acrescenta que a obtenção de 
conhecimento, na perspectiva das TCI, ao ser assumida como possibilidade didática e metodológica, exige que também se execute uma prática docente sedimentada numa lógica inovadora por meio da reflexão aprofundada a respeito das concepções do que é o saber e suas formas de ensinar e aprender.

Ainda que as lives tenham tido uma boa aceitação na comunidade hospitalar, não se pode deixar de mencionar suas limitações. Desse modo, destaca-se que, para o acompanhamento e a participação nas lives, é necessário um dispositivo conectado à Internet, mas nem todos os usuários do sistema público de saúde dispõem dessa tecnologia. Tal fato exclui justamente, em tese, a parcela da população mais carente de educação em saúde, os alijados dos recursos essenciais à manutenção das boas condições de saúde, que não possuem renda para se apropriar de artefatos tecnológicos. Esse fato permite inferir que a utilização exclusiva de lives como veículo para educar em saúde não atende à demanda da população. Por outro lado, ao considerar a impossibilidade das atividades presenciais em decorrência do isolamento social, as lives mostraram-se mais um canal promissor para fortalecer ações educativas.

Especificamente a respeito da situação de exclusão de usuários desprovidos de acesso à ferramenta digital conectada à Internet, o Instituto Brasileiro de Geografia e Estatística (IBGE, 2018) constatou que o telefone celular é o equipamento mais utilizado para acessar a Internet $(98,7 \%)$, mas uma a cada quatro residências no país não dispõe de Internet, tendo os piores índices as regiões Norte (onde apenas 58,4\% da população acima de 10 anos de idade utilizam a Internet) e Nordeste (onde somente 60,1\% usam a Internet). Some-se a esses dados o fato de os usuários do sistema público de saúde, mais especificamente do hospital lócus da pesquisa, serem nordestinos de baixa renda, o que torna a formação excludente, já que é inviável alcançar a todos com igualdade de condições.

A situação é agravada porque pesquisas mostram que, quanto menor o nível de instrução, menos se faz uso da Internet (IBGE, 2018) e as pessoas menos instruídas são justamente as que, possivelmente, mais necessitam de educação em saúde. No mais, a respeito dessa constatação, Delors (1998) e Kenski (2003) enfatizam que não se pode esquecer que muitas pessoas carentes estão afastadas da evolução veiculada pela introdução das TCI na aprendizagem, o que torna a democratização do acesso às TCI para alcance de informação outro desafio atual, para além da pandemia, que requer esforços e mudanças nas esferas econômicas e educacionais de maneira abrangente.

Importa destacar que, mesmo ante dificuldades acarretadas por causa do acesso às tecnologias digitais, o que gera exclusão de alguns grupos, especialmente os menos favorecidos economicamente (BRANDENBURG et al., 2020), o estudo demonstrou que não é apenas possível, mas também relevante a continuidade dos processos formativos mediados pelas lives, porquanto a formação dos profissionais de saúde é uma atividade permanente de elaboração e significação de conhecimento que, da fase escolar e acadêmica, prolonga-se por toda a vida e, em momentos como o da atual crise sanitária, mais do que nunca, requisita ajustes com potencial de superação das restrições à continuidade dos processos formativos na modalidade presencial em meio a essa conjuntura desafiadora.

Observou-se a importância de ressaltar que parte dos procedimentos ensinados e discutidos nas lives foram adotados em ações cotidianas pelos profissionais da saúde, mas, no que concerne à comunidade, de fato não foi possível mensurar como os usuários (re)significaram a nova leitura formativa em termos de ações práticas na realidade em que se inseriam, o que sugere a elaboração de novas pesquisas com esse mote, não esgotando, por conseguinte, a sua análise neste estudo. Todavia, o grupo participante da ação de formação se apropriou dos conhecimentos mediados e, por meio deles, pôde problematizar a atenção à saúde e às experiências em setores específicos do hospital, como saúde materna, infantil e neonatal. Além disso, propiciou-se ressignificar as práticas de profissionais e usuários de modo a qualificá-los em relação aos aspectos emocionais para o enfrentamento da pandemia nas vivências do seu próprio contexto social. 
Notadamente, integrantes da sociedade interagiram por intermédio de mensagem de texto, a título de comentários e indagações, mensagens essas que foram refletidas por ocasião de cada transmissão. Ao considerar essa experiência, infere-se que as apropriações adquiridas mediante o uso de lives podem ampliar saberes capazes de problematizar as situações que demandam intervenção, de modo que a formação continuada colaborou com o conhecimento tanto acerca da saúde quanto sobre vários outros campos da vida social, sendo viável sua efetivação em diversos âmbitos - educacional, político, social etc. - e contextos - especialmente aqueles em que os participantes possuem acesso à Internet e equipamentos digitais adequados para efetivar uma participação qualificada e eficaz pela valorização dos diversos saberes e incentivo à construção compartilhada do conhecimento em saúde. Nesse sentido, o serviço, por meio da própria direção hospitalar, tem dado continuidade às transmissões ao vivo com participação de outros profissionais do hospital e usuários, sempre numa atitude formativa, informativa e cooperativa, na intenção de alcançar, ao mesmo tempo, profissionais da saúde e demais atores sociais envolvidos.

\section{Considerações Finais}

A pesquisa partiu de uma inquietação acerca da possibilidade de as lives serem utilizadas para contribuir com a educação em saúde durante o confinamento social. A inquietude impulsionou o desenvolvimento de uma pesquisa-ação com o escopo de compreender a experiência formativa realizada por meio de lives com a temática "educação em saúde" durante o confinamento social imposto pela Covid-19, mediante parceria constituída entre profissionais de um hospital público estadual de médio porte da cidade de João Pessoa (PB) e professores da UFPB e da UECE.

$\mathrm{Na}$ perspectiva formativa, foram elaboradas, interdisciplinarmente, nove lives pelo Instagram, com mote principal na educação para prevenção, diagnóstico e cuidado com a Covid-19, destinadas a alcançar um público em isolamento social composto por profissionais da saúde e da educação e usuários do sistema público de saúde. Houve a participação on-line, em tempo real, de aproximadamente quatrocentos internautas e 8.855 visualizações posteriores, distribuídas nas nove seções, em apenas um mês. Inclusive, a interação via e-mail e chat também foi muito utilizada para solucionar dúvidas e ensejar satisfação com as lives.

As lives permitiram não apenas confirmar o pressuposto de que ações educativas mediadas por lives colaboram para a disseminação de informações confiáveis e formação em saúde, mas também tornaram factível demonstrar que é possível articular diversos profissionais para atuarem coletivamente como protagonistas e aprendizes no fomento à educação em saúde. Entre os desafios, destacaram-se: a inexperiência de alguns profissionais com o manejo da ferramenta digital utilizada, o que foi contornado com o apoio do setor de comunicação do hospital; e a inacessibilidade às transmissões on-line pelas pessoas mais vulneráveis, que não dispõem de acesso às TCI e/ou Internet, o que gerou a exclusão de um público prioritário.

Em tempos de pandemia, sugere-se que mais pesquisas-ação possam ser desenvolvidas para ampliar a difusão da educação em saúde com vistas a minimizar a contaminação por Covid-19 - que continua a avançar com velocidade inimaginável por diversos países, neste caso, com destaque para o Brasil - a fim de evidenciar outros contextos e novas compreensões sobre a pandemia em diversos campos do saber.

Ressalta-se, por fim, que, desde o início da pandemia, em março de 2020, as lives vêm se destacando como fenômeno bastante usual nas redes sociais por intermédio da Internet. Chamam atenção os usos 
extensivo e intensivo dessa ferramenta, que abrange o mundo corporativo - das escolas, das universidades, entre outros. Interessa destacar, todavia, que o seu uso no campo da saúde, na perspectiva formativa, diferencia-se por serem disseminados conhecimentos essencialmente teóricos e práticos, o que compreende a reflexão sobre as realidades laboral e social, a identificação dos problemas reais ou potenciais e a eleição compartilhada das intervenções nas maneiras como tais profissionais vivenciam esse período da vida. Isso torna factível denotar as possibilidades de alcance ampliado para profissionais ou usuários: interação e dialogicidade_com os participantes por meio das mensagens escritas; e comodidade de acesso nos diversos espaços - domiciliar, trabalhista, entre outros. Contudo, na contramão, como limites, observou-se que a ferramenta, como foi utilizada, não permitiu especificar o público alcançado, já que, teoricamente, o acesso às lives deu-se por diversos usuários da rede eleita para a transmissão. Com isso, exigiu-se o uso de vocabulário isento do tecnicismo peculiar aos profissionais da saúde, a fim de possibilitar a efetiva promoção da educação em saúde.

\section{Agradecimentos}

Agradecemos aos diretores do hospital da Polícia Militar General Edson Ramalho (HPMGER); à assessoria de comunicação social do HPMGER; aos gerentes dos diversos serviços que compõem o hospital; aos servidores do Núcleo de Educação Permanente em Saúde (NEPS); ao CNPQ, pelos apoio financeiro; e a todos os profissionais, convidados e usuários que têm participado e colaborado com a continuidade das ações de Educação Permanente em Saúde, mesmo em momentos deveras desafiadores.

\section{Contribuições dos Autores}

Desenvolvimento do projeto: Neves VNS; Realização da investigação: Neves VNS; Análise formal: Neves VNS; Machado CJS; Conceituação: Neves VNS; Curadoria de dados: Neves VNS; Sabino RN; Redação - Primeira escrita: Neves VNS; Orientação e qualificação do projeto: Machado CJS; Revisão da conceituação: Machado CJS; Supervisão: Machado CJS; Elaboração da metodologia: Fialho LMF; Revisão e edição final: Fialho LMF; Apoio ao desenvolvimento da investigação: Sabino RN; Validação dos resultados: Sabino RN; Validação da redação final: Sabino RN.

\section{Notas}

1. Neste sentido, uma perspectiva sociocultural e crítica do campo pedagógico nos interpela não somente a repensar o espaço limitado das aulas e das escolas, como a reconfigurar um território no qual o mundo opera como pedagogia, sair de opções metodológicas homogeneizantes e voltadas restritamente sobre os processos de ensinar e aprender (DI FRANCO et al., 2020, p. 13, tradução nossa).

2. Em tempos de Covid-19, chamamos a reconstituir pedagogias que apostem em sentidos vitais; afetivas e afetantes, sensíveis e atentas ao mundo, geradoras de outras possíveis narrativas experienciais acerca desses mundos, como formas de viver e sentir em tempos turbulentos, mas também de pensar e experienciar futuros possíveis fora do labirinto (DI FRANCO, et al., 2020, p. 16, tradução nossa). 


\section{Referências}

BAI, Y. et al. Presumed asymptomatic carrier transmission of COVID-19. Journal of the American Medical Association, Chicago, v. 323, n. 14, p. 1406-1407, 2020. https://doi.org/10.1001/jama.2020.2565

BITTENCOURT, F. B.; FIALHO, L. M. F.; PONCE, H. H. Educación a distancia en escuelas públicas de educación secundaria: percepción de los docentes. Temas em Educação, João Pessoa, v. 29, p. 24-41, 2020. https://doi.org/10.22478/ufpb.2359-7003.2020v29n1.51753

BRANDENBURG, C. et al. Cartilha educação e saúde no combate a pandemia da (Covid-19). Práticas Educativas, Memórias e Oralidades, Fortaleza, v. 2, n. 2, p. 1-35, 2020. https://doi.org/10.47149/pemo. v2i2.3670

BRASIL. Ministério da Saúde. Portaria n. 198/GM/MS, de 13 de fevereiro de 2004. Institui a Política Nacional de Educação Permanente em Saúde como estratégia do Sistema Único de Saúde para a formação e desenvolvimento de trabalhadores para o setor e dá outras providências. Diário Oficial da União, Poder Executivo, Brasília, DF, 14 fev. 2004. Disponível em: https://pesquisa.bvsalud.org/bvsms/resource/pt/mis956. Acesso em: 28 maio 2020.

BRASIL. Ministério da Saúde. Secretaria-Executiva. Secretaria de Gestão do Trabalho e da Educação na Saúde. Glossário temático: gestão do trabalho e da educação na saúde. Brasília, DF: Ministério da Saúde, 2012. Disponível em: http://bvsms.saude.gov.br/bvs/publicacoes/glossario_gestao_trabalho_2ed.pdf. Acesso em: 28 maio 2020.

BRASIL. Portaria n. 2.761, de 19 de novembro de 2013. Institui a Política Nacional de Educação Popular em Saúde no âmbito do Sistema Único de Saúde (PNEPS-SUS). Diário Oficial da União, Poder Executivo, Brasília, DF, 20 nov. 2013. Disponível em: https://bvsms.saude.gov.br/bvs/saudelegis/gm/2013/prt2761_19_11_2013. html. Acesso em: 6 jun. 2020.

BRASIL. Laboratório de Inovação em Educação na Saúde com ênfase em Educação Permanente. Brasília, DF: Ministério da Saúde/Organização Pan-Americana da Saúde/Organização Mundial Saúde no Brasil, 2018. (Série Técnica Navegador SUS.) Disponível em: https://iris.paho.org/handle/10665.2/49177. Acesso em: 28 maio 2020.

BRASIL. Lei n. 13.979, de 6 de fevereiro de 2020. Dispõe sobre as medidas para enfrentamento da emergência de saúde pública de importância internacional decorrente do coronavírus responsável pelo surto de 2019. Diário Oficial da União, Poder Executivo, Brasília, DF, 7 fev. 2020. Disponível em: http://www.in.gov.br/en/ web/dou/-/lei-n-13.979-de-6-de-fevereiro-de-2020-242078735. Acesso em: 28 maio 2020.

BRASIL. Coronavírus Brasil. Painel Coronavírus. Brasília, DF: Ministério da Saúde, 22 fev. 2021. Disponível em: https://covid.saude.gov.br/. Acesso em: 23 fev. 2021.

COOKE, W. A foundation correspondence on action research: Ronald Lippitt and John Collier. Manchester: University of Manchester, 1945.

CRESWELL, J. W. Projeto de pesquisa: métodos qualitativo, quantitativo e misto. Trad. Luciana Oliveira da Rocha. 2. ed. Porto Alegre: Artmed, 2007.

DELORS, J. Educação: um tesouro a descobrir. São Paulo: Cortez, 1998. 
DI FRANCO, M. G. et al. Concatenaciones fronterizas: pedagogías, oportunidades, mundos sensibles y COVID-19. Práxis Educativa, Ponta Grossa, v. 24, n. 2, p. 1-18, 2020. https://doi.org/10.19137/ praxiseducativa-2020-240203

ESTELLES, M.; FISCHMAN, G. E. Imagining a post-COVID-19 global citizenship education. Práxis Educativa, Ponta Grossa, v. 15, p. 1-14, 2020. https://doi.org/10.5212/PraxEduc.v.15.15566.051

FANTIN, M. Educação, aprendizagem e tecnologia na pesquisa-formação. Educação \& Formação, Fortaleza, v. 2, n. 3, p. 87-100, 2017. https://doi.org/10.25053/edufor.v216.2377

FONSECA, E.; BIERHALZ, C. D. O contexto local como elo entre ciências da natureza e educação do campo. Educação \& Formação, Fortaleza, v. 3, n. 1, p. 66-84, 2018. https://doi.org/10.25053/redufor. v3i7.172

FREIRE, P. Pedagogia da autonomia: saberes necessários à prática educativa. 25. ed. São Paulo: Paz e Terra, 2002.

FREIRE, P. Pedagogia do oprimido. 50. ed. São Paulo: Paz e Terra, 2011.

GIL, A. C. Como elaborar projetos de pesquisa. 6. ed. São Paulo: Atlas, 2017.

GONÇALVES, Y.; NOGUEIRA, E. G. A educação dos alunos das escolas pantaneiras na perspectiva da educação centrada no aluno. Educação \& Formação, Fortaleza, v. 2, n. 1, p. 87-103, 2017. https://doi. org/10.25053/edufor.v2i4.1922

GUY, R. K. et al. Rapid repurposing of drugs for COVID-19. Science, Washington, v. 368, n. 6493, p. 829830, 2020. https://doi.org/10.1126/science.abb9332

IBGE [INSTITUTO BRASILEIRO DE GEOGRAFIA E ESTATÍSTICA]. Pesquisa Nacional por Amostra de Domicílios (PNAD). Acesso à Internet e à televisão e posse de telefone móvel celular para uso pessoa 2017. Rio de Janeiro: IBGE, 2018. Disponível em: https://biblioteca.ibge.gov.br/index.php/biblioteca-cata logo? view=detalhes\&id=2101631. Acesso em: 10 jun. 2020.

KENSKI, V. M. Tecnologias e ensino presencial e a distância. Campinas: Papirus, 2003.

KÉSIA, A. et al. A pesquisa-ação nas publicações da Revista Brasileira de Educação (2016-2018). Research, Society and Development, Itabira, v. 8, n. 10, e08810720, 2019. https://doi.org/10.33448/rsd-v8i10.720

MARCONI, M. A.; LAKATOS, E. M. Metodologia científica. 6. ed. São Paulo: Atlas, 2011.

MINAYO, M. C. Pesquisa social: teoria, método e criatividade. Petrópolis: Vozes, 2007.

MORAN, J. M. Ensino e aprendizagem inovadores com tecnologias audiovisuais e telemáticas. In: MORAN, J. M.; BEHRENS, M. A.; MASETTO, M. T. (orgs.). Novas tecnologias e mediação pedagógica. 21. ed. Campinas: Papirus, 2013. p. 11-67.

NEVES, V. N. S. Gestão em saúde: uma proposta de melhorias segundo os quatro pilares da educação para o século XXI. 2013. 124 f. Dissertação (Mestrado em Gestão de Organizações Aprendentes) - Programa de Pós-graduação em Gestão de Organizações Aprendentes, Universidade Federal da Paraíba, João Pessoa, 2013. Disponível em: https://repositorio.ufpb.br/jspui/handle/tede/5894. Acesso em: 15 maio 2020. 
ONUBR [ORGANIZAÇÃO DAS NAÇÕES UNIDAS BRASIL]. Transformando nosso mundo: a Agenda 2030 para o desenvolvimento sustentável. Brasil: ONUBR, 2015. Disponível em: https://nacoesunidas.org/pos2015/ agenda2030/. Acesso em: 4 jun. 2020.

PAHO [PAN AMERICAN HEALTH ORGANIZATION]. Folha informativa. Covid-19 (doença causada pelo novo coronavírus), 2020. Disponível em: https://www.paho.org/bra/index.php?option=com_content\&view=arti cle\&id=6101:covid19\&itemid=875\#datas-noticificacoes. Acesso em: 30 maio 2020.

PAHO [PAN AMERICAN HEALTH ORGANIZATION]. Folha informativa. Covid-19 (doença causada pelo novo coronavírus), 12 fev. 2021. Disponível em: https://www.paho.org/bra/index.php?option=com_content\&vie $\mathrm{w}=$ article\&id=6101:covid19\&itemid=875\#datas-noticificacoes. Acesso em: 23 fev. 2021.

SANTOS, J. A. F. Covid-19, causas fundamentais, classe social e território. Trabalho, Educação e Saúde, Rio de Janeiro, v. 18, n. 3, e00280112, 2020. https://doi.org/10.1590/1981-7746-sol00280

SOMEKH, B.; JONES, L. Observação. In: SOMEKH, B.; LEWIN, C. (orgs.). Teoria e métodos de pesquisa social. Trad. Ricardo A. Rosenbusch. Petrópolis: Vozes, 2015. p. 183-191.

SOUZA, K. R.; BRITO, J. C. Gestão do trabalho, educação e saúde: análise de uma experiência de mudança em escola pública. Educação \& Sociedade, Campinas, v. 34, n. 122, p. 267-283, 2013. https://doi.org/10.1590/ S0101-73302013000100015

TRIPP, D. Pesquisa-ação: uma introdução metodológica. Educação e Pesquisa, São Paulo, v. 31, n. 3, p. 443-466, 2005. https://doi.org/10.1590/S1517-97022005000300009

UNESCO [ORGANIZAÇÃO DAS NAÇÕES UNIDAS PARA A EDUCAÇÃO, A CIÊNCIA E A CULTURA]. Consequências adversas do fechamento das escolas. Unesco, 2020a. Disponível em: https://pt.unesco.org/ covid19/educationresponse/consequences. Acesso em: 23 jun. 2020.

UNESCO [ORGANIZAÇÃO DAS NAÇÕES UNIDAS PARA A EDUCAÇÃO, A CIÊNCIA E A CULTURA]. Impacto da Covid-19 na Educação. Unesco, 2020b. Disponível em: https://pt.unesco.org/covid19/ educationresponse. Acesso em: 3 jun. 2020.

VERAS, K.; FERREIRA, H.; LOURINHO, L. Formação de diretores escolares para o programa saúde na escola: uma pesquisa-ação. Educação \& Formação, Fortaleza, v. 5, n. 2, p. 195-215, 2019. https://doi.org/10.25053/redufor. v5i14.898

ZUIN, A. L.; DIAS, J. Formação dos professores que atuam na classe multisseriada na área rural no sul do Amazonas. Educação \& Formação, Fortaleza, v. 2, n. 1, p. 160-180, 2017. https://doi.org/10.25053/edufor.v2i4.1916

\section{Sobre os Autores}

Vanusa Nascimento Sabino Neves é graduada em Enfermagem e mestre em Gestão de Organizações Aprendentes pela Universidade Federal da Paraíba (UFPB). É enfermeira do Hospital da Polícia Militar General Edson Ramalho e da UFPB.

Charliton José dos Santos Machado é licenciado em Ciências Sociais pela Universidade Federal da Paraíba (UFPB). Doutor em Educação pela Universidade Federal do Rio Grande do Norte (UFRN). Professor 
titular e permanente no Programas de Pós-graduação em Educação no Programas de Pós-graduação em Sociologia, ambos na UFPB. Bolsista de Produtividade em Pesquisa CNPQ PQ1-D. Pesquisador do Grupo de Estudos e Pesquisas História da Educação da Paraíba (HISTEDBR/GT-PB).

Lia Machado Fiuza Fialho é licenciada em Pedagogia pela Universidade Estadual do Ceará (UECE), doutora em Educação Brasileira pela Universidade Federal do Ceará (UFCE), professora do Centro de Educação e do Programa de Pós-graduação em Educação, ambos da UECE. Líder do Grupo de Pesquisa Práticas Educativas Memórias e Oralidades (PEMO). Pesquisadora produtividade CNPQ PQ2.

Raquel do Nascimento Sabino é licenciada em Letras e Pedagogia, ambas pela Universidade Federal da Paraíba (UFPB). Doutoranda em Educação pela UFPB. Pesquisadora vinculada ao Grupo de Estudos e Pesquisas História da Educação da Paraíba (HISTEDBR/PB).

Recebido: 27 jul. 2020

Aceito: 17 fev. 2021 